\title{
Transplantation of Cryopreserved Adult Human Schwann Cells Enhances Axonal Conduction in Demyelinated Spinal Cord
}

\author{
Ikuhide Kohama, Karen L. Lankford, Jana Preiningerova, Fletcher A. White, Timothy L. Vollmer and \\ Jeffery D. Kocsis
}

Department of Neurology, Yale University School of Medicine, New Haven, Connecticut 06510, and Paralyzed Veterans of America/Eastern Paralyzed Veterans Association, Neuroscience Research Center and Rehabilitation Research Center, Veterans Affairs Medical Center, West Haven, Connecticut 06516

\begin{abstract}
Schwann cells derived from human sural nerve may provide a valuable source of tissue for a cell-based therapy in multiple sclerosis. However, it is essential to show that transplanted human Schwann cells can remyelinate axons in adult CNS and improve axonal conduction. Sections of sural nerve were removed from amputated legs of patients with vascular disease or diabetes, and Schwann cells were isolated and cryopreserved. Suspensions of reconstituted cells were transplanted into the X-irradiation/ethidium bromide lesioned dorsal columns of immunosuppressed Wistar rat. After 3-5 weeks of extensive remyelination, a typical Schwann cell pattern was observed in the lesion zone. Many cells in the lesion were immunopositive for an anti-human nuclei monoclonal antibody. The dorsal col-
\end{abstract}

Transplantation of exogenous glial cells cultured from fetuses or neonates as well as adults can induce substantial anatomically defined myelination (Blakemore and Crang, 1985; Duncan et al., 1988) and can restore near-normal conduction properties of remyelinated axons in experimental animal models (Utzschneider et al., 1994; Honmou et al., 1996; Imaizumi et al., 1998). Moreover, endogenous remyelination of demyelinated axons by oligodendrocytes (Gledhill et al., 1973) or Schwann cells (Blakemore, 1977) results in the reestablishment of relatively normal impulse conduction in animal models of demyelination (Smith et al., 1979; Blight and Young, 1989; Felts and Smith, 1992), whereas it is very limited in humans in diseases such as multiple sclerosis (Ghatak et al., 1973; Prineas and Connell, 1979; Itoyama et al., 1985). Given the success of using cell transplantation to form functional myelin in animal models, myelin-forming cell transplantation has been suggested as a potential repair strategy for demyelinated CNS axons (Groves et al., 1993; Honmou et al., 1996; Imaizumi et al., 1998).

Transplantation of human glial cells obtained from the adult human brain failed to achieve remyelination of demyelinated rat axons in the CNS (Targett et al., 1996), whereas transplantation of human olfactory ensheathing cells elicited remyelination of demyelinated rat axons in the CNS (Barnett et al., 2000; Kato et

Received July 6, 2000; revised Oct. 26, 2000; accepted Nov. 2, 2000.

This work was supported in part by the Medical Research Service and the Rehabilitation Research and Development Service of the Department of Veterans Affairs, National Multiple Sclerosis Society Grant RG2135, National Institutes of Health Grant NS10174, and the Myelin Project in Washington, DC.

Correspondence should be addressed to Dr. Jeffery D. Kocsis, Department of Neurology, Yale University School of Medicine, Neuroscience Research Center, (127A), VA Medical Center, West Haven, CT 06516. E-mail: jeffery.kocsis@yale.edu. Copyright (C) 2001 Society for Neuroscience 0270-6474/01/210944-07\$15.00/0 umns were removed and maintained in an in vitro recording chamber; the conduction properties were studied using field potential and intra-axonal recording techniques. The transplanted dorsal columns displayed improved conduction velocity and frequency-response properties, and action potentials conducted over a greater distance into the lesion, suggesting that conduction block was overcome. These data support the conclusion that transplantation of human Schwann cells results in functional remyelination of a dorsal column lesion.

Key words: cell transplantation; human Schwann cells; demyelination; restoration of conduction; xenotransplantation; multiple sclerosis

al., 2000). Homologous or autologous tissue represents one possible source of Schwann cells for transplantation into patients with demyelinating disease. Presumably, Schwann cells are not as antigenically predisposed to the immunological attack seen in multiple sclerosis as are oligodendrocytes. However, it is necessary first to demonstrate the remyelinating potential of Schwann cells obtained from adult human nerve. Our results indicate that reconstituted cryopreserved Schwann cells derived from adult human peripheral nerve can remyelinate the demyelinated rat spinal cord and enhance impulse conduction. This demonstration of anatomical and electrophysiological repair of demyelinated axons by adult human Schwann cells is an important prerequisite for future consideration of these cells as candidates for autologous transplantation studies in humans.

\section{MATERIALS AND METHODS}

Preparation of human Schwann cells. Adult human Schwann cells were isolated from sural nerves that were derived from amputated limbs of diabetic or vascular disease patients. Sural nerves were dissected free of epineurium, weighed, minced with a pair of scalpel blades, and incubated for $18.5-20 \mathrm{hr}$ in a $\mathrm{CO}_{2}(5 \%)$ incubator in DMEM containing $10 \%$ fetal calf serum; $1000 \mathrm{U} / \mathrm{ml}$ penicillin and $1000 \mathrm{U}$ streptomycin (Life Technologies, Gaithersburg, MD); $2.5 \mathrm{mg} / 10 \mathrm{ml}$ Collagenase A and $2.5 \mathrm{mg} / 10$ $\mathrm{ml}$ Collagenase D (Roche/Boehringer Mannheim, Indianapolis, IN); and $16 \mathrm{mg} / 10 \mathrm{ml}$ Dispase (Life Technologies). After enzymatic treatment, nerve tissue was mechanically dissociated by trituration and washed three times with DMEM with $10 \%$ fetal calf serum. Cell yields ranged from 4000 to 9000 cells/mg of tissue.

Cryopreservation and cell thawing. Five hundred microliter aliquots of cells $\left(0.5-1.0 \times 10^{6}\right.$ cells $)$ in DMEM with $10 \%$ fetal calf serum were chilled to $4{ }^{\circ} \mathrm{C}$ and mixed $1: 1$ with freezing solution (10\% fetal calf serum, $20 \%$ DMSO with penicillin/streptomycin) on ice. Nunc tubes with cells were placed into the freezing chamber allowing a freezing rate of $-1^{\circ} \mathrm{C} / \mathrm{min}$ in a $-70^{\circ} \mathrm{C}$ freezer. Cells were stored for $2-4$ weeks. Cells in the Nunc tubes were thawed for $60-90 \mathrm{sec}$ in a $37^{\circ} \mathrm{C}$ water bath, washed 


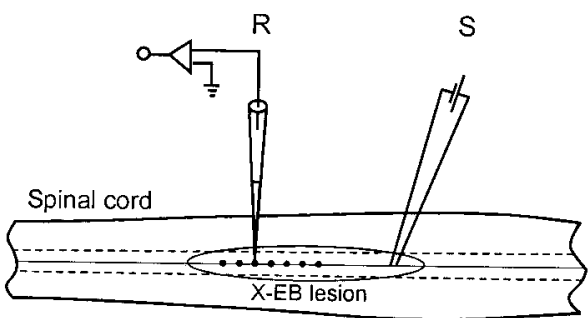

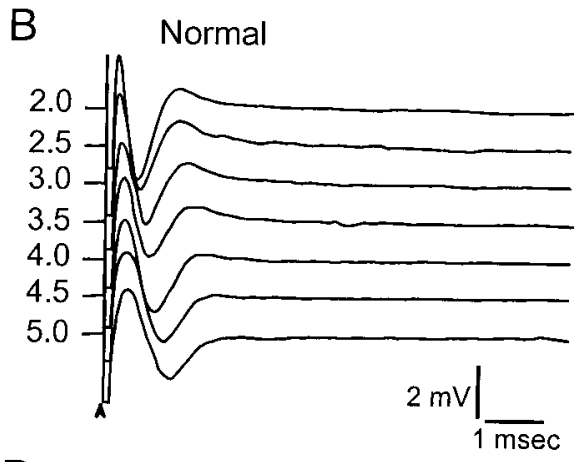

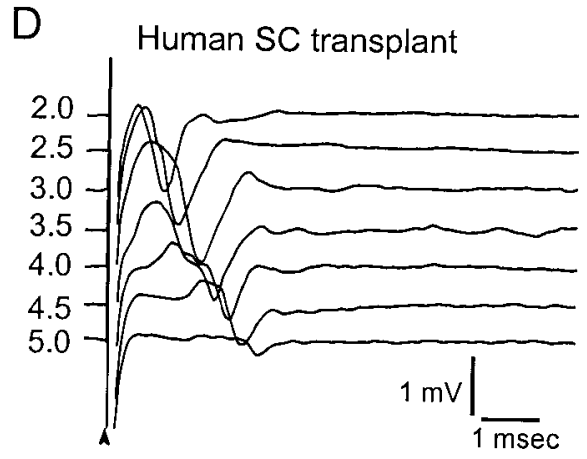

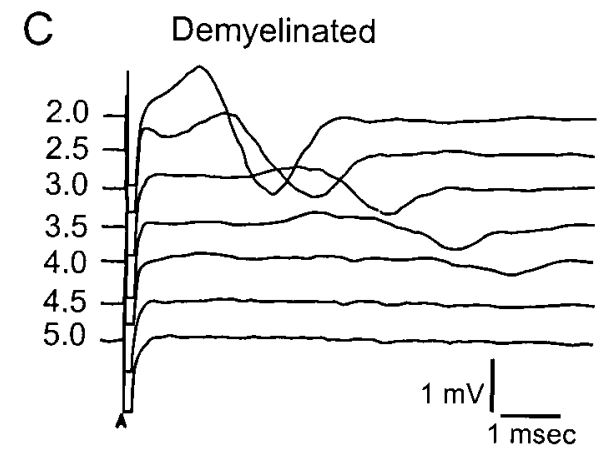

E

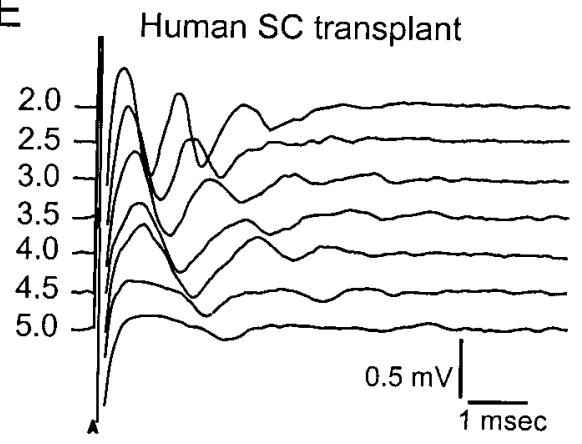

Figure 1. Compound action potentials recorded from control, demyelinated, and transplanted dorsal columns. $A$, Schematic showing the dorsal surface of the spinal cord with the positions of the stimulating $(S)$ and recording $(R)$ electrodes in the dorsal columns. Circled region indicates the area of the X-EB lesion. The position of the recording electrodes is indicated by dots at $0.5 \mathrm{~mm}$ increments along the dorsal columns. $B--E$, Compound action potentials recorded at $0.5 \mathrm{~mm}$ increments along the dorsal columns in normal $(B)$ and demyelinated EB-X lesion, without $(C)$ and with $(D, E)$ transplantation of human Schwann cells. In $E$, note the slow negativities that follow the initial fast negativities. three times, and recounted before transplantation. The density of the cells was adjusted to $30,000 / \mu \mathrm{l}$.

Animal preparation and cell transplantation. Experiments were performed on 22 Wistar rats (8 unoperated control, 7 demyelinated rats, and 7 demyelinated rats with transplants). A focal demyelinated lesion was created in the dorsal column of the spinal cord of 12-week-old rats with $\mathrm{X}$-irradiation and ethidium bromide injection (X-EB) using a method previously described in detail (Honmou et al., 1996). Briefly, rats were anesthetized with ketamine $(75 \mathrm{mg} / \mathrm{kg})$ and xylazine $(10 \mathrm{mg} / \mathrm{kg})$ intraperitoneally, and a $40 \mathrm{~Gy}$ surface dose of X-irradiation was delivered through a $2 \times 4 \mathrm{~cm}$ opening in a lead shield ( $4 \mathrm{~mm}$ thick) to the spinal cord caudal to T10 using a Siemens Stabilipan radiotherapy machine (250 $\mathrm{kV}, 15 \mathrm{~mA}, 0.5 \mathrm{~mm} \mathrm{Cu} ; 1 \mathrm{~mm} \mathrm{Al}$ filters, SDD $28 \mathrm{~cm}$, dose rate 220.9 cGy/min; Siemens AG). Three days after irradiation, rats were anesthetized as described above, and a laminectomy was performed at T11. Using a drawn-glass microelectrode, injections of $0.5 \mu \mathrm{lof} 0.3 \mathrm{mg} / \mathrm{ml} \mathrm{EB}$ in saline were made at depths of 0.7 and $0.5 \mathrm{~mm}$. Three days after EB injection, a bolus of $0.5 \mu \mathrm{l}$ of the human Schwann cell suspension was injected via a glass micropipette into the midpoint of the EB-X-induced lesion 0.7 and $0.5 \mathrm{~mm}$ deep, and the injection site was marked with sterile charcoal. Transplant-receiving rats were immunosuppressed with cyclosporin A $\left(10 \mathrm{mg} \cdot \mathrm{kg}^{-1} \cdot \mathrm{d}^{-1}\right.$, s.c. $)$.

Electrophysiological recording. Rats were killed under sodium pentobarbital anesthesia $(75 \mathrm{mg} / \mathrm{kg}$, i.p.) for physiological experiments 3-5 weeks after cell injection. The vertebral column between T7 and L2 was removed and placed in cold $\left(5^{\circ} \mathrm{C}\right)$ dissecting solution containing (in $\mathrm{mM}$ ): 130 choline chloride, 20 choline bicarbonate, $5.0 \mathrm{KCl}, 5.0 \mathrm{MgCl}_{2}, 0.5$ $\mathrm{CaCl}_{2}, 1.2 \mathrm{NaH}_{2} \mathrm{PO}_{4}$, and 10 dextrose. The spinal cord region between vertebral regions $\mathrm{T} 8$ and $\mathrm{L} 1$ was removed and pinned in a recording chamber perfused with modified Krebs' solution containing (in mM): 124 $\mathrm{NaCl}, 3.0 \mathrm{KCl}, 2.0 \mathrm{MgCl}_{2}, 2.0 \mathrm{CaCl}_{2}, 26 \mathrm{NaHCO}_{3}, 1.3 \mathrm{NaHPO}_{4}$, and 10 dextrose; it was then bubbled with $95 \% \mathrm{O}_{2} / 5 \% \mathrm{CO}_{2}$ at a drip rate of $4.0-5.0 \mathrm{ml} / \mathrm{min}$ at room temperature for $2 \mathrm{hr}$. The electrophysiological recordings were obtained at 26 and $36^{\circ} \mathrm{C}$ for each spinal cord. Electrophysiological studies were not blinded because of the presence of distinctive markings on the spinal cords of control, demyelinated, and transplant groups. However, stimulating and recording parameters were carefully standardized to allow for accurate comparison among the groups.

The surface of the demyelinated lesion was identified by its translucence and the dorsomedial location of a sterile charcoal spot (Schwann cell injection site). A bipolar silver-wire stimulating electrode was placed lightly on the dorsal surface of the spinal cord. Constant-current stimulation pulses were delivered through stimulus isolation units, and a digital timing device controlled the timing of the pulses. Field potential recordings of compound action potentials (CAPs) were obtained with glass microelectrodes $(1-5 \mathrm{M} \Omega ; 1.0 \mathrm{M} \mathrm{NaCl})$ positioned in the dorsal columns (see Fig. 1A), and signals were amplified with a high-input impedance amplifier. The recorded field potentials were positive-negative-positive waves corresponding to source-sink-source currents associated with propagating axonal action potentials (Kocsis and Waxman, 1980); the negativity represents inward current associated with the depolarizing phase of the action potentials. CAP amplitudes were measured from negative peak to second positive peak.

Intra-axonal recordings were obtained with borosilicate electrodes filled with $4 \mathrm{M}$ potassium acetate and $0.1 \mathrm{M} \mathrm{KCl}$. The DC resistance of the microelectrodes ranged from 100 to $150 \mathrm{M} \Omega$. Identification of intraaxonal recordings used criteria that have been discussed previously (Kocsis and Waxman, 1982). Impalements were considered to be intracellular if they displayed a resting potential greater than $-50 \mathrm{mV}$ with spike overshoot and if passage of a constant hyperpolarizing current caused an increase in action potential amplitude (Barrett and Barrett, 1982; Kocsis and Waxman, 1982; Blight and Someya, 1985). Single axon stimulation pulses were provided by the step current command of the recording amplifier and monitored on a separate channel. Constantcurrent pulses were delivered through the recording microelectrode at up 
to $0.5 \mathrm{nA}$ for a duration of $100 \mathrm{msec}$. An active bridge circuit was used to compensate for electrode and preparation resistance. The electrical signals were fed into a computer using commercial software (MP-100; Biopack Systems) through an analog-to-digital converter for on-line processing. A low-pass filter $(5000 \mathrm{~Hz})$ was used for the field potential recordings.

Histological processing and immunocytochemistry. After electrophysiological recordings were obtained, each spinal cord was prepared for histological study. The histological analysis was blinded until completion of the study. The spinal cords were fixed for $24 \mathrm{hr}$ in $2 \%$ paraformaldehyde $/ 2 \%$ glutaraldehyde (w/v in 0.14 m Sorensen's buffer). Tissue was washed three times, stored overnight in buffer, and cut into $2 \mathrm{~mm}$ segments. Then spinal cord segments were post-fixed with $1 \%$ osmium tetroxide (Polysciences, Warrington, PA) for $4 \mathrm{hr}$ and embedded in Epox-812 (Ernest Fullam, Latham, NY). Tissue was serially sectioned on an ultramicrotome, and $1 \mu \mathrm{m}$ sections were collected every $0.25 \mathrm{~mm}$. Finally, the sections were counterstained with $0.5 \%$ methylene blue $/ 0.5 \%$ azure II in $0.5 \%$ borax. Sections were examined with a Nikon Eclipse 800 microscope at $10 \times$ and $100 \times$ and photographed with a Spot RT Color CCD camera.

The spinal cords of some animals were removed, post-fixed overnight, frozen in a cryostat, and cut into $25-\mu \mathrm{m}$-thick sections that were mounted onto Silane-treated slides (Sigma, St. Louis, MO). Tissue sections were rehydrated in phosphate buffer $(\mathrm{PB})$ and preincubated in $10 \%$ normal horse serum and $0.5 \%$ Triton X-100 (Sigma) in PBS for $2 \mathrm{hr}$ at room temperature. Sections were incubated for 16-18 hr at room temperature in Superblock (Pierce) containing 10\% normal horse serum and $0.4 \%$ Triton X-100 plus antiserum to human nuclei (dilution 1:30; Chemicon, Temecula, CA). The antiserum to human nuclei stains nuclei of all human cell types. The slides were then rinsed in PB three times (5 min per rinse) and incubated in fluorescein-conjugated Fab fragment to mouse IgG (dilution 1:500) (ICN Biochemicals, Costa Mesa, CA) for $2 \mathrm{hr}$ at room temperature. Finally sections were rinsed with $\mathrm{PB}$ three times (5 min per rinse), coverslipped using Vectashield (Vector Laboratories, Burlingame, CA), and viewed on a Nikon Eclipse 800 epifluorescent microscope. Two controls were run for all immunocytochemical experiments. Tissue was processed without incubation in either primary or secondary antibody. No immunoreactive cells were observed in either of these controls.

\section{RESULTS}

\section{Enhanced axonal conduction after remyelination by human Schwann cells}

CAPs were recorded with glass microelectrodes in the dorsal columns at $0.5 \mathrm{~mm}$ increments away from a single site of stimulation in normal, demyelinated, and transplanted animals (Fig. $1 A$ ). Recordings from a normal dorsal column at $2.0-5.0 \mathrm{~mm}$ are shown in Figure $1 B$. Note that a single early negativity indicating a relatively homogeneous population of rapidly conducting impulses is recorded from controls. Recordings from similar sites in the demyelinated lesion without transplantation of human Schwann cells are shown in Figure $1 C$; a considerable increase in latency is apparent, indicating conduction slowing. Moreover, no response was observed in the demyelinated axons at $4.5 \mathrm{~mm}$ and beyond in the lesion zone, indicating conduction block.

The CAPs recorded from the transplant group showed a CAP with either a single early negativity (Fig. $1 D$ ) or two prominent negative potentials (i.e., an initial early negativity followed by a later negativity; Fig. $1 E$ ). CAPs were recorded throughout the 5 $\mathrm{mm}$ lesion zone in the transplant group, indicating the overcoming of conduction block (note recognizable responses at 4.5 and $5.0 \mathrm{~mm}$ in Figure $1, D$ and $E$, and a lack of response in $C$ ). Conduction velocity was studied at both 26 and $36^{\circ} \mathrm{C}$ and was greater for normal, demyelinated, and remyelinated axons at $36^{\circ} \mathrm{C}$ (Fig. $2 A$ ). At $36^{\circ} \mathrm{C}$, conduction velocity of the early negativity in controls was $11.03 \pm 1.78 \mathrm{~m} / \mathrm{sec}(n=7)$ and $1.02 \pm 0.21 \mathrm{~m} / \mathrm{sec}$ $(n=6)$ in the demyelinated dorsal columns. In the transplanted group, conduction velocity of the early response was $2.95 \pm 1.09$
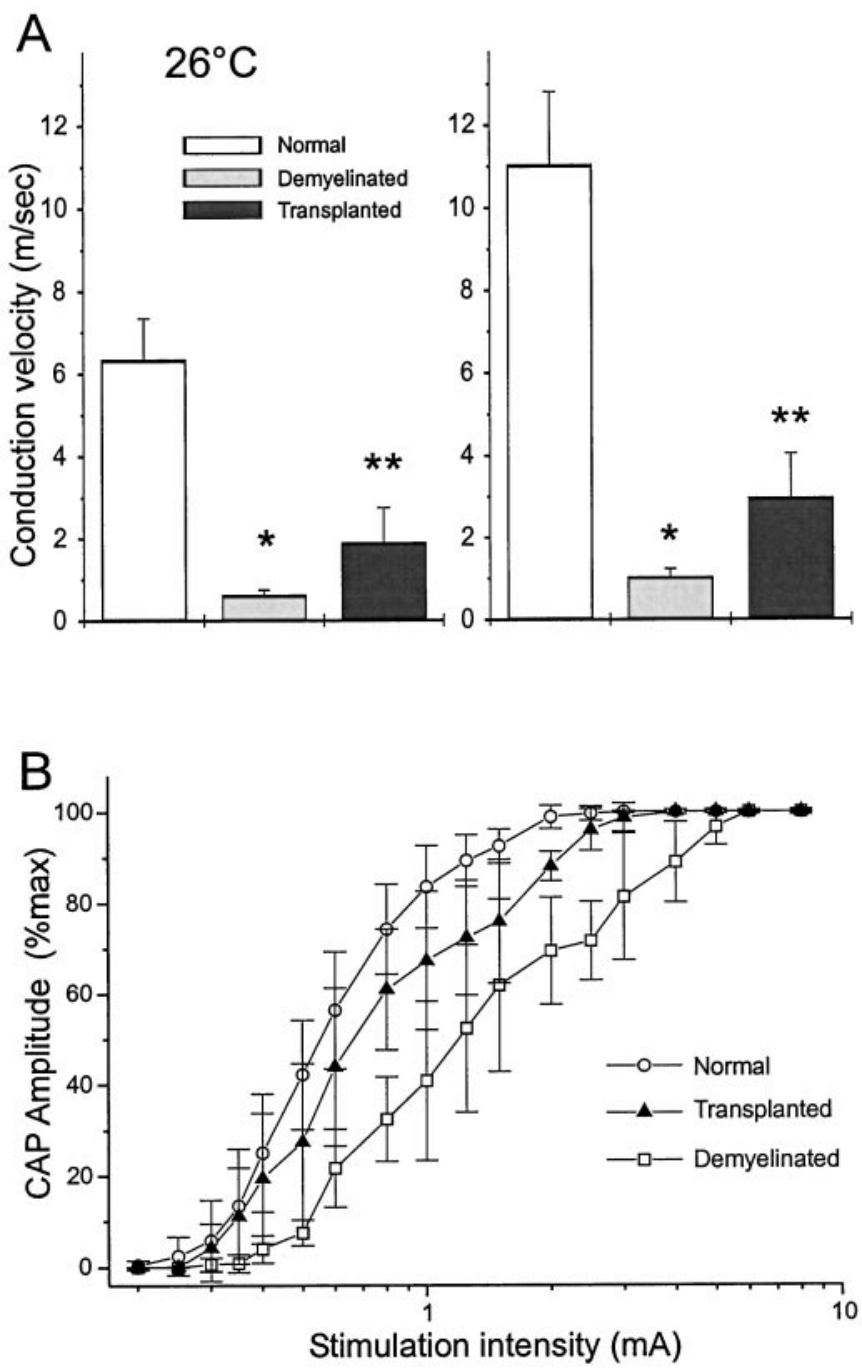

Figure 2. Conduction velocity of control, demyelinated, and remyelinated axons. $A$, Conduction velocity (error bars indicate SEM) of dorsal column axons obtained from normal (control), demyelinated, and transplanted human Schwann cells at $26^{\circ} \mathrm{C}$ (left) and $36^{\circ} \mathrm{C}$ (right). Conduction velocity is nearly doubled at $36^{\circ} \mathrm{C}$, as compared with $26^{\circ} \mathrm{C}$ for the three experimental conditions. ${ }^{*} p<0.001$, control $(n=7)$ versus demyelinated $(n=6)$ at $26^{\circ} \mathrm{C}$ and $36^{\circ} \mathrm{C} ; * * p<0.01$, demyelinated $(n=6)$ versus transplanted $(n=6)$. $B$, Stimulus-response curves for normal, demyelinated, and transplanted groups.

$\mathrm{m} / \mathrm{sec}(n=6)$. A summary of these results with statistical significance is shown graphically in Figure $2 A$.

The stimulus-response curve in Figure $2 B$ provides additional information showing restoration of electrical properties of the axons subsequent to human Schwann cell transplantation. The stimulus-response threshold was increased in the demyelinated axons as compared with controls from $0.33 \pm 0.05 \mathrm{~mA}$ to $0.48 \pm$ $0.06 \mathrm{~mA}(n=5 ; p<0.01)$. This is commensurate with the expected higher threshold of nonmyelinated axons. Moreover, the stimulus intensity necessary to obtain a maximal CAP was also increased in the demyelinated axons $(2.10 \pm 0.36 \mathrm{~mA}$ vs $4.8 \pm 0.6$ $\mathrm{mA} ; n=5 ; p<0.01)$. However, in the transplanted group, neither the threshold $(0.39 \pm 0.06 \mathrm{~mA} ; n=6 ; p=0.076)$ nor the stimulus intensity necessary to induce a maximal response $(2.75 \pm 0.37$ $\mathrm{mA} ; n=6 ; p=0.017$ ) was significantly different from controls.

Conduction velocity was also studied in single axons of the 

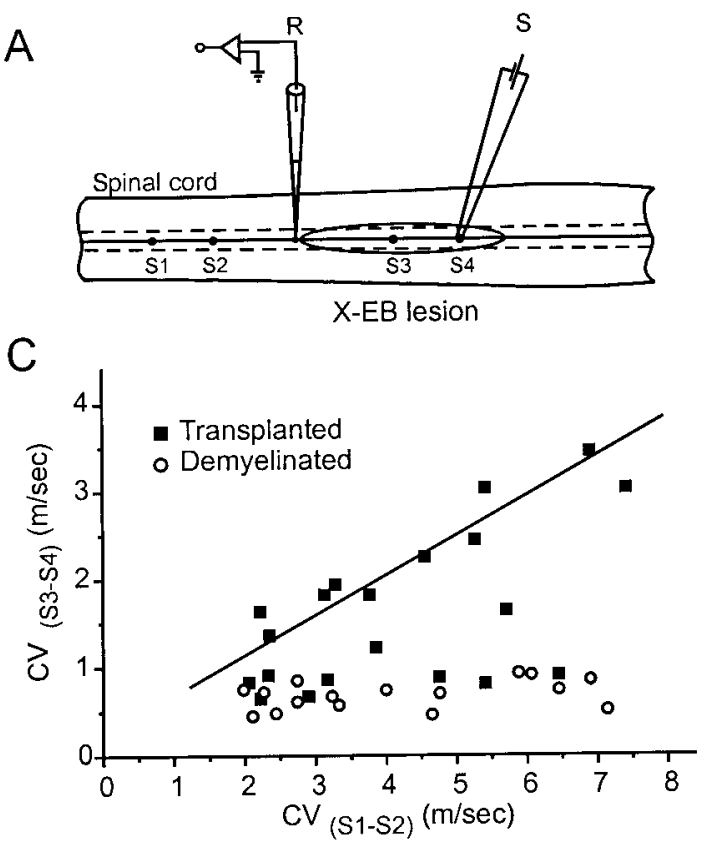

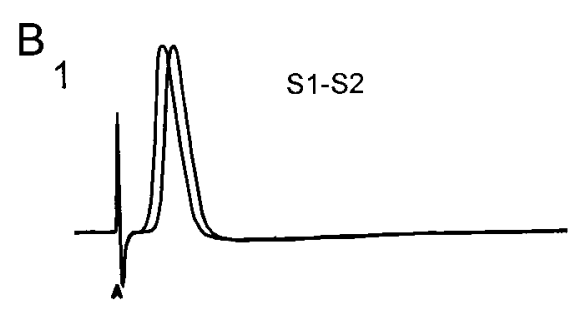

2
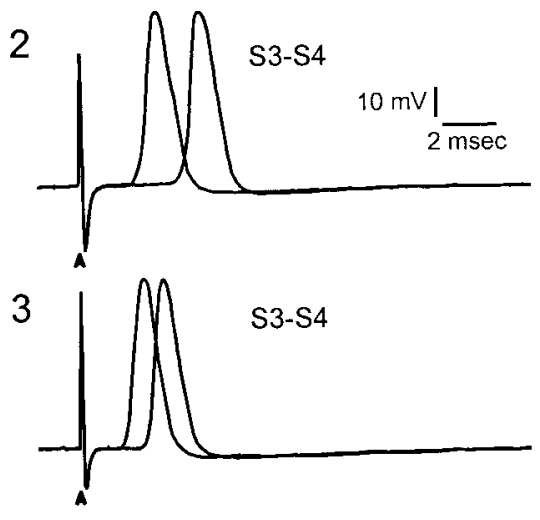

Figure 3. Intra-axonal recordings from demyelinated and remyelinated dorsal column axons. $A$, Schematic showing arrangement of intra-axonal recording and stimulation sites. Intra-axonal recordings were obtained from dorsal column axons outside of the lesion where the axons were normally myelinated. Stimulating electrodes were positioned outside $(S 1-S 2)$ and within $(S 3-S 4)$ the $X-E B$ lesion zone to assess single axon conduction velocity over both the demyelinated or remyelinated axon segment and the normally myelinated axon segment of the same axon. $B, 1-3$, Pairs of action potentials recorded from $S 1-S 2$ stimulation (1), S3-S4 in the demyelinated dorsal columns (2), and S3-S4 after cell transplantation (3). Recordings were obtained at comparable conduction distances. $C$, Plot of the conduction velocity $(C V)$ of axon segments within the lesion (S3-S4) versus conduction velocity of the axon segment outside of the lesion (S1-S2) for X-EB-lesioned spinal cord without $(\bigcirc)$ and with (ם) transplantation. dorsal column using intra-axonal recording techniques. Arrays of stimulating electrodes were placed on the spinal cord dorsum within the lesion and on the control (uninjured) dorsal column several millimeters away (Fig. $3 A$ ). Axons were then impaled at a site between the two arrays of stimulating electrodes within the nondemyelinated region, thus permitting study of conduction velocity of demyelinated-remyelinated and normal segments of the same axon. In the X-EB lesion (see Materials and Methods), the portion of the axon passing through the region of demyelination (Fig. 3B2) exhibited considerably longer latencies, indicative of slower conduction velocity than the nondemyelinated region of the same tract (Fig. 3B1). A plot of conduction velocity of the axon trajectory between the S1 and S2 stimulation sites (outside of lesion) versus conduction velocity between the S3 and S4 sites (within the lesion) for demyelinated and transplant groups is shown in Figure $3 C$. Conduction velocity for all of the demyelinated axons $(n=16)$ was $<1.0 \mathrm{~m} / \mathrm{sec}(0.68 \pm 0.16 \mathrm{~m} / \mathrm{sec})$. In contrast, after cell transplantation, 12 of 20 single axons had conduction velocities through the site of remyelination greater than the demyelinated population $(2.22 \pm 0.69 \mathrm{~m} / \mathrm{sec} ; p<0.001)$. Thus, this population of axons had conduction velocities 3.3 times greater than the demyelinated population. The remaining eight axons in the transplant group had conduction velocities of $0.86 \pm$ $0.17 \mathrm{~m} / \mathrm{sec}$ that did not differ from the demyelinated axons. These data suggest that a large subpopulation of axons in the demyelinated lesion was remyelinated by cell transplantation and the remaining axons were not. This agrees with the field potential analysis in which early and late negativities could be recorded in the transplant group (Fig. 1E).

Paired stimulus pulses were applied to study the recovery (refractory) properties of the axons; interstimulus intervals ranged from 0.5 to $100 \mathrm{msec}$. CAP amplitude recovery of the test response (second of the pair) was delayed in the demyelinated regions as compared with controls (Fig. 4A). Recovery in the transplantation group was also reduced, as compared with control, but less than for the demyelinated axons. The ability of dorsal column axons to transmit trains of action potentials was examined by frequency-response analysis using $25-200 \mathrm{~Hz}$ stim- ulus trains ( $0.5 \mathrm{sec}$ duration). Normal dorsal column axons displayed an amplitude decrement of $\sim 22 \%$ of initial amplitude at $200 \mathrm{~Hz}$ (Fig. 4B). The demyelinated axons showed a greater amplitude decrement than controls at 50, 100, 150, and $200 \mathrm{~Hz}$. The reduction at $200 \mathrm{~Hz}$ was $\sim 80 \%$, compared with $22 \%$ for controls. However, after human Schwann cell transplantation, the axons showed considerable restoration in their ability to follow high-frequency stimulation (Fig. 4B).

\section{Histological pattern of remyelination and identification of donor cells within the lesion}

After in vitro electrophysiological recordings were obtained from the transplanted dorsal columns, the spinal cords were placed in fixative and subsequently prepared as either plastic-embedded sections or frozen sections for immunohistochemical analysis (See Materials and Methods). Although fixation was not optimal because the spinal cords were first used for in vitro electrophysiological recordings, it was adequate to demonstrate remyelination. The demyelinating lesion (Fig. 5A) occupied the central region of the dorsal columns for nearly the entire dorsoventral extent. It is important to note that, in the X-EB lesion model, virtually no myelin is present in the lesion for 6-8 weeks (Blakemore and Patterson, 1978; Honmou et al., 1996; Imaizumi et al., 1998). Large areas of remyelination were observed in the rats that showed recovery of electrophysiological function. In Figure $5 B$, a field of remyelinated axons can be seen within the central region of a dorsal column transplanted with human Schwann cells. Electrophysiological recordings from this spinal cord indicated rapid impulse conduction as compared with the nontransplant spinal cords. Many of the axons displayed a peripheral (Schwann celllike) pattern of myelination characterized by large cytoplasmic and nuclear domains adjacent to the remyelinated axon (Fig. 5B, arrowheads). Although remyelination was observed throughout the lesion, some areas showed a paucity of myelinated axons.

To provide further evidence that transplanted human Schwann cells were responsible for the remyelination, donor cells in the lesion site were immunostained by an anti-human nuclei monoclonal antibody. Low- and high-power bright-field photomicro- 

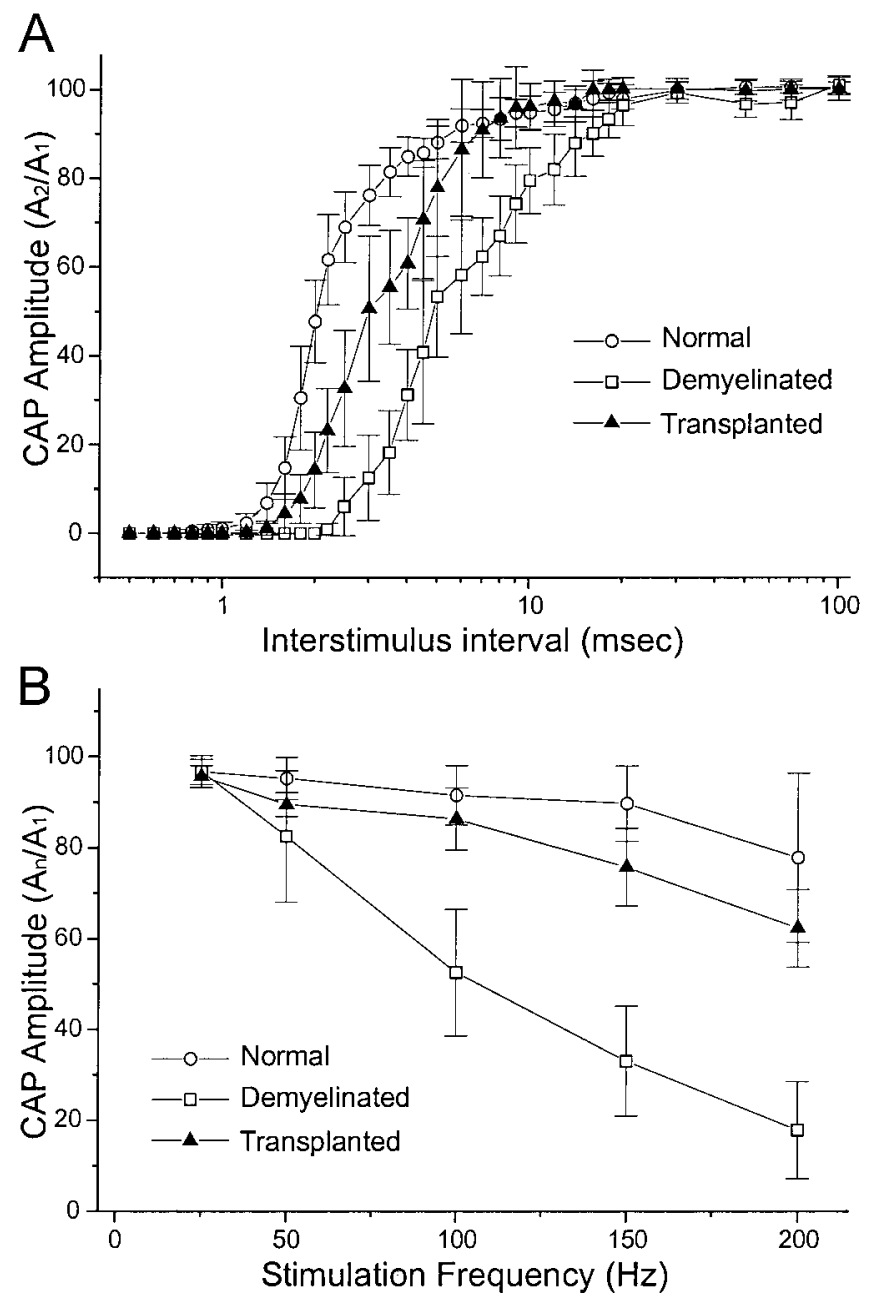

Figure 4. Frequency-response properties of control, demyelinated, and remyelinated axons. $A$, Amplitude recovery for the second response of paired-pulse stimuli at varying interstimulus intervals for normal, demyelinated, and transplanted groups. $A_{2} / A_{1}$ indicates the ratio of the amplitudes of the second response of the stimulus pair (test) divided by the first (control) response. There is less amplitude decrement for the transplanted axons than for the demyelinated axons. Amplitude is normalized as that of the last divided by the first response. $B$. Frequency-response properties for normal, demyelinated, and transplanted groups. $A_{n} / A_{1}$ indicates the ratio of the amplitudes of the last response of the stimulus train divided by the first (control) response for each frequency tested. Train duration was $0.5 \mathrm{sec}$. The demyelinated axons display considerable reduction in their ability to follow high-frequency stimulation, but the transplanted axons are able to follow higher frequencies of stimulation approaching that of normal axons.

graphs of a frozen section through the lesion site are shown in Figure 6, $A$ and $C$, respectively. Figure 6, $B$ and $D$, which correspond to $A$ and $C$, reveal an anti-human nuclear antibody-positive hypercellular mass of transplanted human Schwann cells. These labeled cells are limited to the ovoid lesioned area of the dorsal columns.

\section{DISCUSSION}

Although oligodendrocytes are the cells that normally myelinate CNS axons, peripheral myelin-forming cells such as Schwann cells (Blakemore and Crang, 1985; Honmou et al., 1996) and olfactory ensheathing cells (Franklin et al., 1996; Imaizumi et al., 1998) can myelinate CNS axons in vivo and restore nearly normal conduction properties (Honmou et al., 1996; Imaizumi et al.,
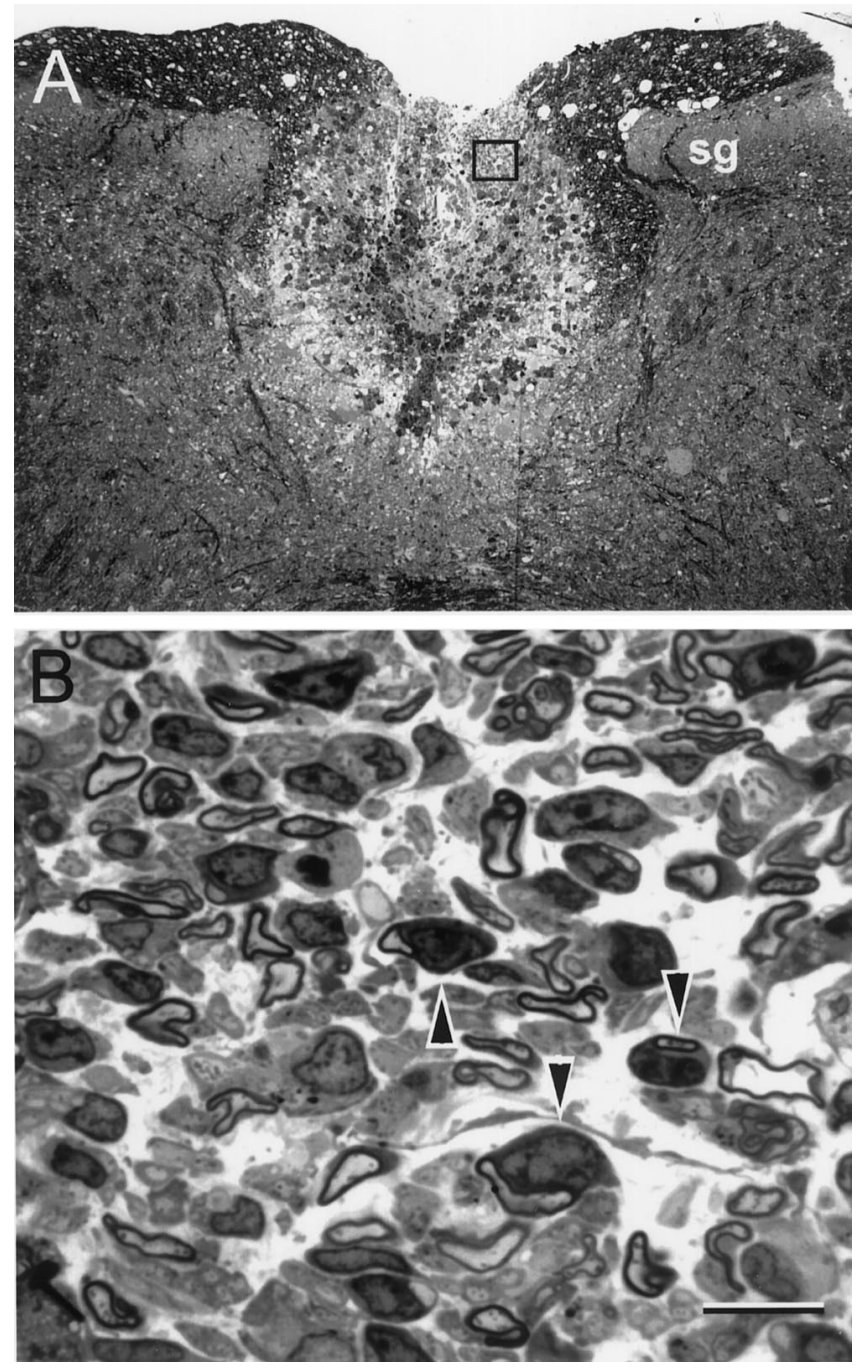

Figure 5. Axons remyelinated after human Schwann cell transplantation show a peripheral pattern of myelination. Photomicrographs were obtained from spinal cords placed in fixative after in vitro electrophysiological recordings shown in Figure $1 D$ were obtained. $A$, Lesion area of dorsal columns 3 weeks after induction of the X-EB lesion. sg, Substantia gelatinosa of the dorsal horn. $B$, Higher-power micrograph from the boxed region of the lesion showing remyelinated axons. Arrowheads indicate examples of axons myelinated by cells with large nuclear and cytoplasmic domains characteristic of peripheral myelin. Scale bar: $A, 100 \mu \mathrm{m} ; B, 10$ $\mu \mathrm{m}$.

1998). A distinct advantage in a cell-based treatment for multiple sclerosis is that peripheral myelin-forming cells presumably do not exhibit the antigenic properties of oligodendrocytes. Moreover, the relative effectiveness of adult human Schwann cells in forming myelin in the adult rat is in contrast to the relative ineffectiveness of adult human oligodendrocytes in remyelinating adult rat white matter (Targett et al., 1996).

Transplantation of human oligodendrocytes derived from adult human brain white matter failed to form a myelin sheath when transplanted into demyelinated rat spinal cord (Targett et al., 1996). The transplanted human oligodendrocytes survived in the demyelinated lesion; however, no myelin sheaths were formed, and there was no evidence of cell migration or division (Targett et al., 1996), leading to the conclusion that most oligodendrocytes in the adult human brain white matter have little if any remyelinating potential. Several lines of evidence support this view. 

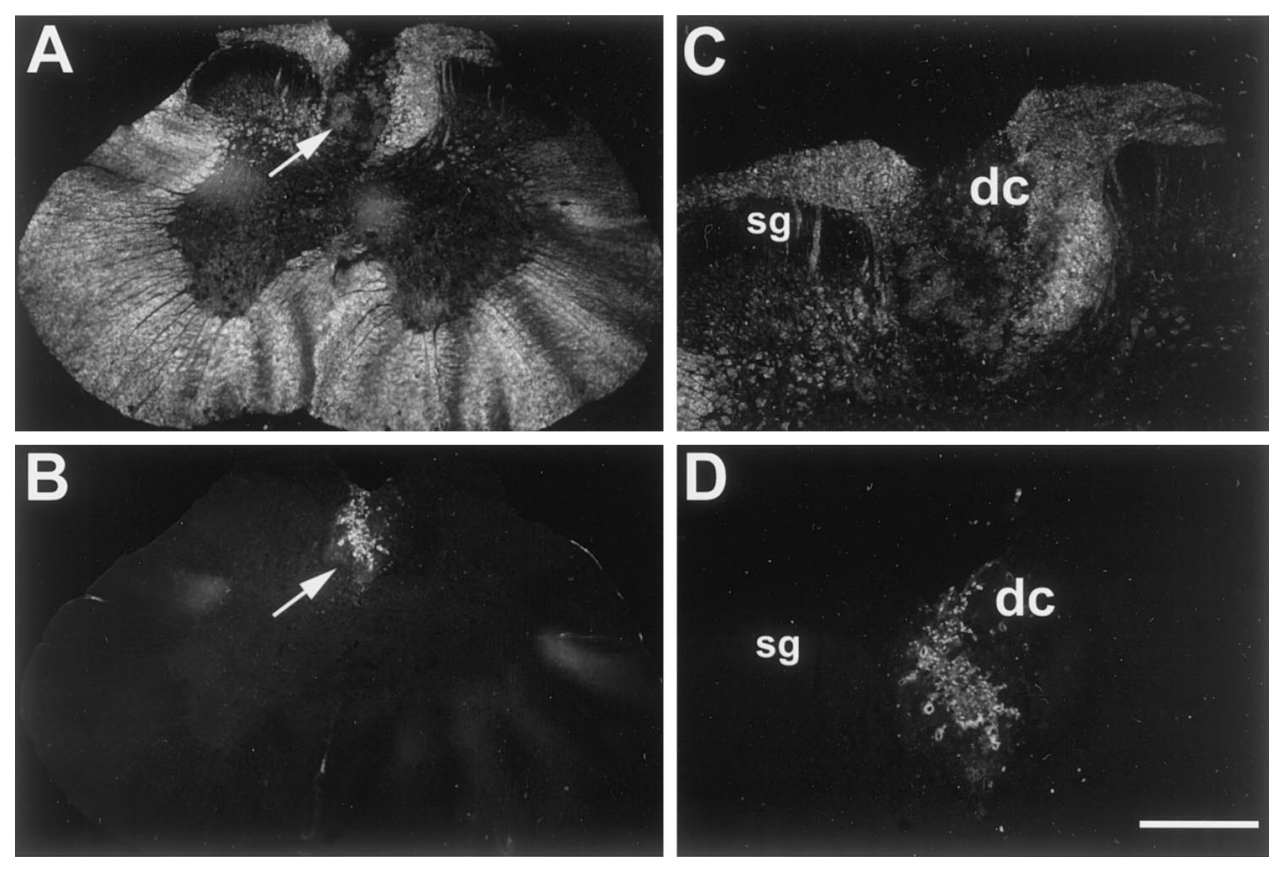

Figure 6. Immunolabeled cells with antibody against human nuclei. Photomicrograph depicts a transverse section of the spinal cord at the level of T10 5 weeks after injection of human Schwann cells. A, Lowpower dark-field image of T10 spinal cord showing structures of spinal cord and lesioned dorsal column (arrow). B, Lowpower fluorescent photomicrograph of the same section as $A$, exhibiting transplanted FITC-positive cells immunolabeled with antibody against human nuclei. Note the lack of immunopositive cells outside of the lesion site. $C$, High-power dark-field image through adjacent section of spinal cord exhibiting cellular elements present in lesioned dorsal column $(A$, arrow). $D$, Highpower fluorescent photomicrograph of the same section as $C$, exhibiting immunopositive cells labeled with anti-human nuclei conjugated to FITC. sg, Substantia gelatinosa; $d c$, dorsal columns. Scale bar: $A, C$, $550 \mu \mathrm{m} ; B, D, 250 \mu \mathrm{m}$.

Culture experiments indicate that human oligodendrocytes make contact with axons, but no myelin is formed when human white matter glia are cocultured with rodent dorsal root ganglion cells (Whittemore et al., 1993). In contrast to human oligodendrocytes derived from the adult, human embryonic oligodendrocyte precursors can myelinate rat axons in the immature CNS in vivo (Gumpel et al., 1987), as can human Schwann cells in the PNS (Levi and Bunge, 1994).

\section{Anatomical repair of demyelinated axons by human Schwann cells}

In the present study, we demonstrate that transplanted Schwann cells derived from adult human nerves are able to remyelinate demyelinated CNS axons in vivo and improve conduction in the adult rat spinal cord. Two lines of evidence indicate that the remyelination was indeed from the transplanted human cells and not from endogenous remyelination by resident rat Schwann cells. First, the lesion was induced by $\mathrm{X}$-irradiation of the spinal cord to inhibit endogenous mitosis, followed by ethidium bromide injection into the cord to kill white matter glial cells. This protocol induces a glial-free zone in the dorsal columns of the spinal cord with no endogenous myelination for at least 6-8 weeks (Kocsis and Waxman, 1980). The spinal cords were studied at 3 weeks after cell injection, a time point well within the window in which no endogenous remyelination occurs. Second, we confirmed survival of human donor cells by identifying immunopositive cells that were restricted to the dorsal columns using an anti-human nuclei monoclonal antibody; extensive labeling of donor cells was seen throughout the remyelinated zone of the dorsal columns.

The myelin-forming cells had large nuclear and cytoplasmic domains characteristic of peripheral myelin (Berthold, 1978). Although the remyelination was relatively extensive, pockets of remyelinated axons with intermittent areas of demyelinated axons were observed. Yet, the extent of remyelination was sufficient to observe markedly improved conduction as assayed by both field potential and intra-axonal recording.

\section{Restoration of electrophysiological function of axons remyelinated by human Schwann cells}

Demyelination results in conduction slowing and varying amounts of conduction block. Our field potential recordings indicate two important points: (1) the population of fibers in the transplant zone, as a whole, shows an increase in average conduction velocity and the ability to sustain high-frequency firing, and (2) responses (although attenuated) can be recorded for greater longitudinal distances into the lesion, suggesting that conduction block is overcome. Conduction velocity was greater in the transplanted animals but less than in control. The intra-axonal and morphological observations shed some light on a possible reason for this difference. Although many single remyelinated axons showed marked improvement in conduction velocity, a number of axons conducted slowly and did not show evidence of remyelination. Together, the interspersed islands of Schwann cells, which are closely associated with myelinated axons, and the presence of some demyelinated axons suggest that the average conduction velocity as recorded by field potentials was reduced because of the mixing of remyelinated and demyelinated axons in the dorsal columns. Nonetheless, these results indicate that a significant number of axons were remyelinated for an extensive longitudinal distance within the lesion.

\section{Human Schwann cells as a potential source for cell transplantation in humans}

An important consideration in the development of a potential cell therapy approach to repair the damaged CNS in humans is the selection of an appropriate donor cell type. The demonstration of the myelinating potential of adult human Schwann cells derived from adult nerve indicates the potential of autologous Schwann cell transplantation as a repair strategy for demyelinated CNS axons. However, harvesting sufficient numbers of Schwann cells from peripheral nerve biopsy without cell expansion imposes limitations. Expansion of the cells may resolve this problem, but the myelinating potential of the expanded cells is yet to be determined. It is important that our results were from cryopreserved cells that had been reconstituted at the time of cell 
transplantation. This suggests that harvested cells can be cryopreserved and stored for potential future use.

Advances in stem cell research and the development of human clonal neural precursor cells derived from either embryonic or adult CNS may allow for an abundant source of myelin-forming cells. Learish and colleagues (1999) demonstrated that fetal neural stem cells can be treated to establish self-renewing pre-O2-A progenitors. These cells form extensive oligodendrocyte myelination when transplanted into the myelin-deficient neonatal rat. Recently, Brustle and collaborators (1999) further demonstrated that human embryonic stem cell-derived glial precursors can be used as a source of myelinating transplants. Advances in the cell biology of progenitor cells derived from embryonic, fetal, or adult CNS opens the prospect of developing cell lines as a potential source of a cell therapy for demyelinating diseases. However, the demonstration here that cryopreserved adult human Schwann cells can remyelinate and restore conduction in the demyelinated rat spinal cord indicates the feasibility of an autologous cell therapy approach in humans.

\section{REFERENCES}

Barnett SC, Alexander CL, Iwashita Y, Gilson J, Crowther J, Clark L, Dunn LT, Papanastassiou V, Kennedy PGE, Franklin RJM (2000) Identification of a human olfactory ensheathing cell that can effect transplant-mediated remyelination of demyelinated CNS axons. Brain 123:1581-1588.

Barrett EF, Barrett JN (1982) Intracellular recording from vertebrate myelinated axons: mechanism of the depolarizing afterpotential. J Physiol (Lond) 323:117-144.

Berthold CH (1978) Morphology of normal peripheral axons. In: Physiology and pathobiology of axons (Waxman SG, ed), pp 3-64. New York: Raven.

Blakemore WF (1977) Remyelination of CNS axons by Schwann cells transplanted from the sciatic nerve. Nature 266:68-69.

Blakemore WF, Crang AJ (1985) The use of cultured autologous Schwann cells to remyelinate areas of persistent demyelination in the central nervous system. J Neurol Sci 70:207-223.

Blakemore WF, Patterson RC (1978) Suppression of remyelination in the CNS by X-irradiation. Acta Neuropathol (Berl) 42:105-113.

Blight AR, Someya S (1985) Depolarizing afterpotentials in myelinated axons of mammalian spinal cord. Neuroscience 15:1-12.

Blight AR, Young W (1989) Central axons in injured cat spinal cord recover electrophysiological function following remyelination by Schwann cells. J Neurol Sci 91:15-34.

Brustle O, Jones KN, Learish RD, Karram K, Choudhary K, Wiestler OD, Duncan ID, McKay RD (1999) Embryonic stem cell-derived glial precursors: a source of myelinating transplants. Science 285:754-756.

Duncan ID, Hammang JP, Jackson KF, Wood PM, Bunge RP, Langford L (1988) Transplantation of oligodendrocytes and Schwann cells into the spinal cord of the myelin-deficient rat. J Neurocytol 17:351-360.
Felts PA, Smith KJ (1992) Conduction properties of central nerve fibers remyelinated by Schwann cells. Brain Res 574:178-192.

Franklin RJ, Gilson JM, Franceschini IA, Barnett SC (1996) Schwann cell-like myelination following transplantation of an olfactory bulbensheathing cell line into areas of demyelination in the adult CNS. Glia 17:217-224.

Ghatak NR, Hirano A, Doron Y, Zimmerman HM (1973) Remyelination in multiple sclerosis with peripheral type myelin. Arch Neurol 29:262-267.

Gledhill RF, Harrison BM, McDonald WI (1973) Pattern of remyelination in the CNS. Nature 244:443-444.

Groves AK, Barnett SC, Franklin RJ, Crang AJ, Mayer M, Blakemore WF, Noble M (1993) Repair of demyelinated lesions by transplantation of purified O-2A progenitor cells. Nature 362:453-455.

Gumpel M, Lachapelle F, Gansmuller A, Baulac M, Baron van Evercooren A, Baumann N (1987) Transplantation of human embryonic oligodendrocytes into shiverer brain. Ann NY Acad Sci 495:71-85.

Honmou O, Felts PA, Waxman SG, Kocsis JD (1996) Restoration of normal conduction properties in demyelinated spinal cord axons in the adult rat by transplantation of exogenous Schwann cells. J Neurosci 16:3199-3208.

Imaizumi T, Lankford KL, Waxman SG, Greer CA, Kocsis JD (1998) Transplanted olfactory ensheathing cells remyelinate and enhance axonal conduction in the demyelinated dorsal columns of the rat spinal cord. J Neurosci 18:6176-6185.

Itoyama Y, Ohnishi A, Tateishi J, Kuroiwa Y, Webster HD (1985) Spinal cord multiple sclerosis lesions in Japanese patients: Schwann cell remyelination occurs in areas that lack glial fibrillary acidic protein (GFAP). Acta Neuropathol (Berl) 65:217-223.

Kato T, Honmou O, Uede T, Hashi K (2000) Transplantation of human olfactory ensheathing cells elicits remyelination of demyelinated rat spinal cord. Glia 30:209-218.

Kocsis JD, Waxman SG (1980) Absence of potassium conductance in central myelinated axons. Nature 287:348-349.

Kocsis JD, Waxman SG (1982) Intra-axonal recordings in rat dorsal column axons: membrane hyperpolarization and decreased excitability precede the primary afferent depolarization. Brain Res 238:222-227.

Learish RD, Brustle O, Zhang SC, Duncan ID (1999) Intraventricular transplantation of oligodendrocyte progenitors into a fetal myelin mutant results in widespread formation of myelin. Ann Neurol 46:716-722.

Levi AD, Bunge RP (1994) Studies of myelin formation after transplantation of human Schwann cells into the severe combined immunodeficient mouse. Exp Neurol 130:41-52.

Prineas JW, Connell F (1979) Remyelination in multiple sclerosis. Ann Neurol 5:22-31.

Smith KJ, McDonald WI, Blakemore WF (1979) Restoration of secure conduction by central demyelination. Trans Am Neurol Assoc 104:25-29.

Targett MP, Sussman J, Scolding N, O'Leary MT, Compston DA, Blakemore WF (1996) Failure to achieve remyelination of demyelinated rat axons following transplantation of glial cells obtained from the adult human brain. Neuropathol Appl Neurobiol 22:199-206.

Utzschneider DA, Archer DR, Kocsis JD, Waxman SG, Duncan ID (1994) Transplantation of glial cells enhances action potential conduction of amyelinated spinal cord axons in the myelin-deficient rat. Proc Natl Acad Sci USA 91:53-57.

Whittemore SR, Sanon HR, Wood PM (1993) Concurrent isolation and characterization of oligodendrocytes, microglia and astrocytes from adult human spinal cord. Int J Dev Neurosci 11:755-764. 